\title{
Correlation of psychomotor skills and didactic performance among dental students in Saudi Arabia
}

This article was published in the following Dove Press journal:

Advances in Medical Education and Practice

15 October 2013

Number of times this article has been viewed

\author{
Ahmed R Afify' \\ Khalid H Zawawi' \\ Hisham I Othman ${ }^{2}$ \\ Ayman A Al-Dharrab ${ }^{3}$ \\ 'Department of Preventive Dental \\ Sciences, ${ }^{2}$ Department of Basic Oral \\ and Clinical Sciences, ${ }^{3}$ Department of \\ Oral and Maxillofacial Rehabilitation, \\ Faculty of Dentistry, King Abdulaziz \\ University, Jeddah, Saudi Arabia
}

Objectives: The objective of this study is to investigate the correlation between the psychomotor skills and the academic performance of dental students.

Methods: Didactic and preclinical scores were collected for students who graduated from the Faculty of Dentistry, King Abdulaziz University, Jeddah, Saudi Arabia, in 2011. Three courses (Dental Anatomy, Removable Prosthodontic Denture, and Orthodontics) were selected. Correlations comparing didactic and practical scores were done for the total samples, then for the males and females separately.

Results: There was no significant correlation between the practical and didactic scores for the three courses for the total sample. There was a significant correlation between all three subjects in the didactic scores. For females, the results showed that there was only a significant correlation between the practical and didactic scores for Dental Anatomy. For males, no correlation was observed between the practical and didactic scores for all subjects.

Conclusion: In the present sample, didactic performance did not correlate well with the students' psychomotor performance.

Keywords: psychomotor performance, didactic performance, dental students, correlation study, dental education, practical performance

\section{Introduction}

In many health professions and in dentistry in particular, the acquisition of psychomotor skills is highly important for a successful professional. ${ }^{1}$ In dental practices, psychomotor skills are involved in performing different procedures that require handeye coordination with cognitive planning. The daily dental practice includes a wide range of procedures of variable complexity, requiring different levels of psychomotor skills. These procedures might include several tasks, for example, wire bending during orthodontics, carving a tooth from a wax block, and performing cavity preparation on a tooth during restorative dental work.

The Dental Admission Test, which includes a hand skills part, was introduced at the beginning of the 1950s and is still in use but with some modifications. Several investigators found that these tests have a moderate correlation value with the subsequent clinical performance of the students. ${ }^{2-4}$ Therefore, some researchers recommended other means to verify the psychomotor skills of dental candidates. Some suggested psychometric tests. ${ }^{5,6}$ Others suggested a specially designed practical test, ${ }^{7-9}$ while several suggested only interviewing the candidates. ${ }^{10,11}$

Despite these dental school admission tests, there are a number of students who are unable to acquire the necessary dental skills to complete the required projects
Correspondence: Khalid H Zawawi

Department of Preventive Dental Science, Faculty of Dentistry, King Abdulaziz University, PO Box 80209, Jeddah, 21589, Saudi Arabia

Tel +96626402000 ext 20388

Fax+96626403316

Email kzawawi@kau.edu.sa 
during their preclinical practical sessions in a timely manner. ${ }^{5,8,12-14}$

The complexity of the skills needed dictates that the dental students should have ample opportunity and spend the necessary time to develop and to gain these essential psychomotor skills through different teaching techniques during their preclinical laboratory projects. These projects vary from the use of traditional bench top exercises including dental phantom lab manikins to highly sophisticated devices, such as the virtual reality simulators. ${ }^{15,16}$

At the Faculty of Dentistry at King Abdulaziz University, the admission criteria are based mainly on didactic examination scores. Only applicants who had a score of $95 \%$ or above in their high school diploma were selected. These candidates are then required to take written exams in general and scientific knowledge, followed by a formal interview. Although this admission procedure is demanding, it only tests the intellectual ability of the candidates and does not evaluate their psychomotor skills or their manual competence. Even though the students' grade point averages have been moderately successful in predicting student performance in dental school, this and other methods of assessing dental school candidates do not predict how well the students will perform during their dental education.

The aim of this study was to investigate the correlation between the didactic scores of dental students with their psychomotor skills in the form of their preclinical laboratory projects. Since males and females in the Dental School are taught independently, their grades were analyzed collectively and separately.

\section{Materials and methods}

Available didactic and preclinical scores were collected for students who graduated from the Faculty of Dentistry,
King Abdulaziz University, in 2011. Three courses (Dental Anatomy, Removable Prosthodontic Denture, and Orthodontics), which were given during the third, fourth, and fifth years, respectively, were selected. Students who repeated any of the three courses were eliminated, yielding a sample size of 86 students, 31 males and 55 females.

Each course required the completion of didactic and preclinical practical components. The practical modules were chosen to represent a practical assessment of each student's visual-spatial perception and fine hand-eye coordination. The practical modules comprised wire-bending exercises, carving teeth from plaster, teeth set-up, and fabrication of partial dentures.

Each student's practical exercise was graded on the basis of the criteria described in the handout distributed to the students. Before grading the students' work, senior faculty members, who are directors of the preclinical laboratory courses, participated in a calibration session. The three faculty members involved in the course completed the evaluation of each student independently. Averaging the three faculty grades derived the final grade. The faculty members involved in the grading remained unaware of each student's score as graded by the other two faculty members. This study was reviewed and approved by the Research Ethics Committee at the Faculty of Dentistry, King Abdulaziz University.

\section{Statistical analysis}

The Pearson product-moment correlation comparing practical scores and didactic scores was performed. The analysis was conducted for the total sample, and then it was repeated for males and females separately.

Statistical analysis was performed using the Statistical Package for the Social Sciences software version 20.0 for Mac (IBM Corporation, Armonk, NY, USA).

Table I Pearson product-moment correlations between practical scores and didactic scores for both females and males

\begin{tabular}{|c|c|c|c|c|c|c|}
\hline & \multicolumn{3}{|l|}{ Practical } & \multicolumn{3}{|l|}{ Didactic } \\
\hline & Orthodontics & $\begin{array}{l}\text { Dental } \\
\text { anatomy }\end{array}$ & $\begin{array}{l}\text { Removable } \\
\text { prosthodontics }\end{array}$ & Orthodontics & $\begin{array}{l}\text { Dental } \\
\text { anatomy }\end{array}$ & $\begin{array}{l}\text { Removable } \\
\text { prosthodontics }\end{array}$ \\
\hline \multicolumn{7}{|l|}{ Practical } \\
\hline Orthodontics & - & 0.201 & $0.306^{*}$ & 0.129 & 0.095 & 0.018 \\
\hline Dental anatomy & & - & $0.394 *$ & $0.286 *$ & 0.197 & 0.118 \\
\hline Removable prosthodontics & & & - & 0.148 & 0.176 & 0.094 \\
\hline \multicolumn{7}{|l|}{ Didactic } \\
\hline Orthodontics & & & & - & $0.611 *$ & $0.532^{*}$ \\
\hline Dental anatomy & & & & & - & $0.711 *$ \\
\hline Removable prosthodontics & & & & & & - \\
\hline
\end{tabular}

Note: *Correlation is significant at the 0.01 level (two-tailed). 
Table 2 Pearson product-moment correlations between practical scores and didactic scores for females

\begin{tabular}{|c|c|c|c|c|c|c|}
\hline & \multicolumn{3}{|l|}{ Practical } & \multicolumn{3}{|l|}{ Didactic } \\
\hline & Orthodontics & $\begin{array}{l}\text { Dental } \\
\text { anatomy }\end{array}$ & $\begin{array}{l}\text { Removable } \\
\text { prosthodontics }\end{array}$ & Orthodontics & $\begin{array}{l}\text { Dental } \\
\text { anatomy }\end{array}$ & $\begin{array}{l}\text { Removable } \\
\text { prosthodontics }\end{array}$ \\
\hline \multicolumn{7}{|l|}{ Practical } \\
\hline Orthodontics & - & $0.330 *$ & $0.442 * *$ & 0.142 & 0.15 & 0.119 \\
\hline Dental anatomy & & - & $0.403^{* *}$ & $0.374 * *$ & $0.370 * *$ & 0.242 \\
\hline Removable prosthodontics & & & - & 0.225 & $0.269 *$ & 0.244 \\
\hline \multicolumn{7}{|l|}{ Didactic } \\
\hline Orthodontics & & & & - & $0.708^{* *}$ & $0.621 * *$ \\
\hline Dental anatomy & & & & & - & $0.691 * *$ \\
\hline Removable prosthodontics & & & & & & - \\
\hline
\end{tabular}

Notes: *Correlation is significant at the 0.05 level (two-tailed); **correlation is significant at the 0.01 level (two-tailed).

\section{Results}

Table 1 shows that there was no correlation between the practical and didactic scores for the three courses for the total sample.

However, there was a positive correlation between practical Removable Prosthodontic scores and both Orthodontic and Dental Anatomy scores (Table 1). Also, there was a significant correlation between all three subjects in the didactic scores.

Additional correlation analyses for females and males independently were performed. For females, the results showed that there was a significant correlation between the practical and the didactic scores for the Dental Anatomy scores while there was no correlation observed between practical and didactic scores for both Removable Prosthodontics and Orthodontics (Table 2).

When analyzing the outcome of the males, no correlation was observed between the practical and didactic scores for all subjects (Table 3 ).

\section{Discussion}

This study showed for the first time that dental students who perform well in their didactic courses may not perform equally in their practical projects, and the opposite is true. The correlational analysis between didactic and practical scores for the female students was relatively more significant compared to the male students.

The medical and paramedical profession, in its many facets, makes extensive use of the three major learning domains - cognitive, affective, and psychomotor. ${ }^{17}$

Psychomotor skills in dental practice are involved in activities that require not only hand-eye coordination but also cognitive planning. These skills might involve several tasks (for example, control of an orthodontic plier, control of bur movement used for restorative work, or the use of hand instruments in periodontal treatment).

During dental education, students are given the opportunity to develop their psychomotor skills. This varies from the use of the traditional bench top exercises including manikins to high-technology devices, such as virtual reality simulators; ${ }^{15,16}$ however, these tasks require the integration of their theoretical knowledge. Some argued that in as much as tests for noncognitive psychomotor skills are not used during dental school admission procedures; schools must depend on application information consisting of predental grade point averages and the battery of dental admission tests. ${ }^{12,18}$

Table 3 Pearson product-moment correlations between practical scores and didactic scores for males

\begin{tabular}{|c|c|c|c|c|c|c|}
\hline & \multicolumn{3}{|l|}{ Practical } & \multicolumn{3}{|l|}{ Didactic } \\
\hline & Orthodontics & $\begin{array}{l}\text { Dental } \\
\text { anatomy }\end{array}$ & $\begin{array}{l}\text { Removable } \\
\text { prosthodontics }\end{array}$ & Orthodontics & $\begin{array}{l}\text { Dental } \\
\text { anatomy }\end{array}$ & $\begin{array}{l}\text { Removable } \\
\text { prosthodontics }\end{array}$ \\
\hline \multicolumn{7}{|l|}{ Practical } \\
\hline Orthodontics & - & -0.016 & -0.016 & 0.134 & 0.031 & -0.095 \\
\hline Dental anatomy & & - & $0.397^{*}$ & 0.198 & 0.003 & 0.13 \\
\hline Removable prosthodontics & & & - & -0.06 & -0.029 & -0.163 \\
\hline \multicolumn{7}{|l|}{ Didactic } \\
\hline Orthodontics & & & & - & 0.228 & 0.276 \\
\hline Dental anatomy & & & & & - & $0.596 * *$ \\
\hline Removable prosthodontics & & & & & & - \\
\hline
\end{tabular}

Notes: *Correlation is significant at the 0.05 level (two-tailed); **correlation is significant at the 0.01 level (two-tailed). 
The finding of this study seems to support the concept of applying a battery of dental admission tests prior to the enrollment of dental students. Colleges that do not incorporate a practical component into their dental admission protocol are encouraged to implement practical tests during the dental admission test. One limitation to the current finding of this study is that only one group of students was selected and evaluated. Another limitation is the sample size. A follow-up study that will look at different courses for different graduating classes is warranted to confirm the finding of this study.

\section{Conclusion}

In the present sample, didactic performances did not correlate well with the students' psychomotor performances.

\section{Disclosure}

The authors report no conflicts of interest in this work.

\section{References}

1. Tedesco LA. Issues in dental curriculum development and change. J Dent Educ. 1995;59(1):97-147.

2. Gansky SA, Pritchard H, Kahl E, et al. Reliability and validity of a manual dexterity test to predict preclinical grades. J Dent Educ. 2004;68(9): 985-994.

3. Kingsley K, Sewell J, Ditmyer M, O'Malley S, Galbraith GM. Creating an evidence-based admissions formula for a new dental school: University of Nevada, Las Vegas, School of Dental Medicine. J Dent Educ. 2007;71(4): 492-500.

4. Kress GC Jr, Dogon IL. A correlational study of preadmission predictor variables and dental school performance. J Dent Educ. 1981;45(4): 207-210.
5. Boyle AM, Santelli JC. Assessing psychomotor skills: the role of the Crawford Small Parts Dexterity Test as a screening instrument. J Dent Educ. 1986;50(3):176-179.

6. Zullo TG. A factor analysis of perceptual and motor abilities of dental students. J Dent Educ. 1971;35(6):356-361.

7. Brigante RF, Lamb RE. Perception and control test: the dental technical aptitude test of the future? J Dent Educ. 1968;32(3):340-354.

8. Walcott AM, Knight GW, Charlick RE. Waxing tests as predictors of students' performance in preclinical dentistry. J Dent Educ. 1986;50(12):716-721.

9. Wilson S, Suddick RP, Shay JS, Hustmyer FE Jr. Correlations of scores on embedded figures and mirror tracing with preclinical technique grades and PMAT scores of dental students. Percept Mot Skills. 1981;53(1):31-35.

10. Röding K. A new admission procedure to dental education at The Karolinska Institute. An initial evaluation. Eur J Dent Educ. 1997;1(3): 114-122.

11. Röding K. Professional competence in final-year dental undergraduates: assessment of students admitted by individualised selection and through traditional modes. Eur J Dent Educ. 2001;5(1):12-16.

12. Gray SA, Deem LP. Predicting student performance in preclinical technique courses using the theory of ability determinants of skilled performance. J Dent Educ. 2002;66(6):721-727.

13. Kao EC, Ngan PW, Wilson S, Kunovich R. Wire-bending test as a predictor of preclinical performance by dental students. Percept Mot Skills. 1990;71(2):667-673.

14. Suddick RP, Yancey JM, Wilson S. Mirror-tracing and Embedded Figures tests as predictors of dental students' performance. $J$ Dent Educ. 1983;47(3):149-154.

15. Wierinck E, Puttemans V, Swinnen S, van Steenberghe D. Effect of augmented visual feedback from a virtual reality simulation system on manual dexterity training. Eur J Dent Educ. 2005;9(1):10-16.

16. Wierinck E, Puttemans V, van Steenberghe D. Effect of tutorial input in addition to augmented feedback on manual dexterity training and its retention. Eur J Dent Educ. 2006;10(1):24-31.

17. Orlich DC, Harder RJ, Callahan RC, Trevisan MS, Brown AH. Teaching Strategies: A Guide to Effective Instruction. 9th ed. Boston: Wadsworth; 2009.

18. Gray SA, Deem LP, Straja SR. Are traditional cognitive tests useful in predicting clinical success? J Dent Educ. 2002;66(11):1241-1245.
Advances in Medical Education and Practice

\section{Publish your work in this journal}

Advances in Medical Education and Practice is an international, peerreviewed, open access journal that aims to present and publish research on Medical Education covering medical, dental, nursing and allied health care professional education. The journal covers undergraduate education, postgraduate training and continuing medical education
Dovepress

including emerging trends and innovative models linking education, research, and health care services. The manuscript management system is completely online and includes a very quick and fair peer-review system. Visit http://www.dovepress.com/testimonials.php to read real quotes from published authors. 